\title{
Students' Reasoning About Whether to Report When Others Cheat: Conflict, Confusion, and Consequences
}

\author{
Talia Waltzer $^{1}$ (D) $\cdot$ Arvid Samuelson $^{1} \cdot$ Audun Dahl $^{1}$
}

Accepted: 2 April 2021 / Published online: 12 April 2021

(c) The Author(s) 2021

\begin{abstract}
Nearly all students believe academic cheating is wrong, yet few students say they would report witnessed acts of cheating. To explain this apparent tension, the present research examined college students' reasoning about whether to report plagiarism or other forms of cheating. Study 1 examined students' conflicts when deciding whether to report cheating. Most students gave reasons against reporting a peer (e.g., social and physical consequences, a lack of responsibility to report) as well as reasons in favor of reporting (e.g., concerns about welfare, justice, and fairness). Study 2 provided experimental confirmation that the contextual factors referenced by Study 1 participants in fact influenced decisions about whether to report cheating. Overall, the findings indicate that students often decide against reporting peers' acts of cheating, though not due to a lack of concern about integrity. Rather, students may refrain from reporting because of conflicting concerns, lack of information about school policy, and perceived better alternatives to reporting.
\end{abstract}

Keywords Academic integrity · Third-party intervention · Moral reasoning · Plagiarism • Academic policy $\cdot$ Reporting

When students witness their peers violating academic integrity policies, they face a dilemma: Should they report their peers' cheating to the school? By holding each other accountable, students can foster communities of academic integrity (Burrus et al., 2013; McCabe \& Treviño, 1993). Many university policies require students to report any witnessed violations of academic integrity (e.g., in honor code schools; Arnold et al., 2007; McCabe et al., 2001). Most students encounter cheating in college (Baird, 1980; Brown, 2002; McCabe et al., 2012; Murdock et al., 2016; Whitley, 1998), and students overwhelmingly believe cheating is wrong (Davis et al., 1992; Semerci, 2006). Believing that cheating is wrong provides a clear reason for reporting cheating, but very few students are willing to report violations that they witness (Jendrek, 1992; Lim \& See, 2001; Rennie \& Crosby, 2002; Yachison et al., 2018). This apparent tension between negative attitudes toward cheating and the refusal to report cheating suggests that students' decisions about reporting are more complex than scholars and educators might assume.

Talia Waltzer

twaltzer@ucsc.edu

1 Department of Psychology, University of California, Santa Cruz, CA 95064, USA 
Why do students refrain from reporting cheating, even though they say cheating is wrong? One possible explanation is that students simply do not care about academic integrity, and their rejections of cheating are insincere. Alternatively, students may decide against reporting because they prioritize competing concerns (e.g., others' welfare), are unfamiliar with school policies, or perceive better alternatives to reporting. In Study 1, we investigated potential barriers to reporting by interviewing undergraduate students about why they would be willing - or unwilling - to report a peer. Then, to test whether the concerns identified in Study 1 would influence students' decisions, Study 2 manipulated these factors in surveys that prompted students to decide whether to report a peer.

\section{Academic Cheating and Plagiarism}

We define academic cheating - referred to in this paper as cheating-as an academic action that violates institutional rules and would yield academic advantages to one or more students if carried out successfully (Barnhardt, 2016; Cizek, 2003; Murdock et al., 2016). Examples of cheating include bringing prohibited crib notes into an exam or giving homework answers to a classmate (Waltzer et al., 2017). Plagiarism, a subtype of cheating, involves presenting others' words or ideas as one's own in an academic assignment (Moss et al., 2018; Park, 2003). Plagiarism can be more ambiguous than other forms of cheating, and students who plagiarize often do not realize they are doing so (Gullifer \& Tyson, 2014; Pennycook, 1996; Power, 2009; Waltzer et al., 2017). Thus, reasons against reporting plagiarism (e.g., insufficient evidence, uncertainty about the plagiarizer's intentions) could be distinct from reasons against reporting cheating in general (e.g., social repercussions, consequences to the cheater). Unlike prior work (Harding et al., 2007; Jendrek, 1992; McCabe et al., 2012; Rennie \& Crosby, 2002; Yachison et al., 2018), the present research examined reasoning about plagiarism separately from reasoning about other forms of cheating.

Students frequently encounter a variety of cheating in school. Decades of research have documented that most students cheat at least once in college (Davis et al., 1992; Genereux \& McLeod, 1995; McCabe et al., 2012; Murdock et al., 2016; Park, 2003; Stone et al., 2009; Whitley, 1998; Yardley et al., 2009). Students also seem to be aware of their peers' cheating. For example, Brown (2002) found that $94 \%$ of senior nursing students had witnessed cheating. Moreover, many students are asked by their peers to participate in facilitating dishonesty (Scrimpshire et al., 2017).

\section{How do Students Decide Whether to Report Cheating?}

Despite their frequent encounters with cheating, few students-in some studies as few as 1\%-say they are willing to report cheating to a teacher (Baird, 1980; Burton \& Near, 1995; Jendrek, 1992; Lim \& See, 2001; Nuss, 1984; Stone et al., 2009). This is true even as many students say they should report cheating (Jendrek, 1992; Rennie \& Crosby, 2002; Yachison et al., 2018). In an experimental setting, Yachison et al. (2018) found that when students were not asked any questions about a peer's act of cheating on an exam, only $9 \%$ of students proactively reported cheating, but when asked direct questions about the cheating incident, $63 \%$ of students reported the cheating behavior to the experimenter. These choices depended on contextual factors: Students were less likely to report if they were 
collaborating with the cheater and more likely to report if they were being graded relative to the cheater (Yachison et al., 2018; see also Scrimpshire et al., 2017).

Students' unwillingness to report cheating may seem surprising given evidence that people often protest, report, or otherwise intervene on perceived wrongdoing, even when the interveners are not directly affected by the violations (Darley \& Latané, 1968; Dozier \& Miceli, 1985; Fehr \& Fischbacher, 2003, 2004; Henrich et al., 2006; Jackson et al., 2014; Latané \& Darley, 1970; Latané \& Nida, 1981; Near \& Miceli, 1985; Philpot et al., 2020). Why do so few students report acts of cheating to their schools, sometimes in violation of institutional encouragement and honor codes? Here, we consider four possible factors: (1) competing considerations, (2) informational assumptions about school policies, (3) perception of better alternatives, and (4) lack of care about academic integrity.

\section{(1) Competing Considerations}

One explanation for why students refrain from reporting is that they are faced with a dilemma: On one hand, students disapprove of cheating (Davis et al., 1992); on the other hand, they perceive reasons against reporting a peer (Rennie \& Crosby, 2002). In responding to such conflicts, people need to balance competing concerns, ultimately prioritizing one over the other (Keeney \& Raiffa, 1976; Kohlberg, 1971; Nucci, 2004; Turiel, 2015; Turiel \& Dahl, 2019; Waytz et al., 2013). In deciding whether to report cheating, students may balance concerns about reputational backlash or harmful consequences to the reported cheater against their concerns about the wrongness of cheating (Nitsch et al., 2005; Pupovac et al., 2019). Hence, students may sometimes refrain from reporting cheating because other concerns seem more important, not because they disregard the value of academic integrity. Existing research on students' reasoning about reporting is limited, and most previous studies have either tested explanatory factors pre-determined by the researchers (Jenkel \& Haen, 2012; Pupovac et al., 2019) or obtained qualitative responses from small focus groups (Rennie \& Crosby, 2002). The present research used open-ended interview prompts and manipulated scenarios in surveys to examine the considerations influencing students' decisions about whether to report.

\section{(2) Informational Assumptions}

A second possible contributor is students' beliefs about policies and facts regarding academic integrity. Informational assumptions about the world guide many social evaluations and decisions (Ajzen et al., 2011; Neff \& Helwig, 2002; Turiel et al., 1991, 1987; Wainryb, 1991). Prior research suggests that students in schools with an honor code understand their academic policy better (Schwartz et al., 2013), and students in honor code schools are more willing than students in non-honor code schools to report cheating (Arnold et al., 2007; McCabe et al., 2001). Many of the reasons that students hold against reporting (e.g., unclear guidelines, the futility of reporting, and requirement of proof; Pupovac et al., 2019; Rennie \& Crosby, 2002) rest on students' beliefs about the process and consequences of reporting cheating. If students lack information about the process of reporting, or if they believe that reporting would ruin the cheater's life (Nitsch et al., 2005), they may refrain from reporting despite a general concern with integrity. The present research examined students' statements about rules and consequences of reporting to assess the relation between informational assumptions and decisions to report. 


\section{(3) Better Alternatives}

A third explanation is that students prefer alternative ways of responding to cheating. For instance, a student may have accurate knowledge about academic integrity policies and want to stop the cheating yet choose to confront the cheater instead of reporting to the instructor. In this way, students may resolve the dilemma of whether to report by finding an alternative solution besides reporting or doing nothing. If so, studies focused on reporting as the sole response to cheating may overlook high rates of other interventions. The present research analyzed participant statements for suggestions of alternative actions.

\section{(4) Lack of Care}

A fourth possible explanation for low rates of reporting is that students refrain from reporting because they find cheating acceptable and do not care that other students cheat. Indeed, some scholars have argued that students think cheating is "not a big deal" since "everyone cheats," and that moral judgments about right and wrong play a minimal role in decisions about cheating (Houston, 1976, p. 301; see also Brown, 2002; McCabe, 1997; McCabe et al., 2012; Sykes \& Matza, 1957). As one prominent researcher put it, "Morality does not seem to be a major influence on student decisions to cheat or not to cheat" (McCabe, 1997, p. 444). If students view cheating as normal or acceptable, they should express little or no reason to report cheating and experience little conflict. In contrast, recent evidence suggests that most students judge cheating as wrong in most situations (Baird, 1980; Davis et al., 1992; Jensen et al., 2002; Semerci, 2006; Waltzer et al., 2019). Consistent with their judgments, most students avoid cheating in most cases (Levine et al., 2010; Rundle et al., 2019; Waltzer et al., 2019). Their judgments that cheating is wrong are rooted in concerns beyond just avoiding sanctions, such as fairness, academic standards, honesty, and others' welfare (Miller et al., 2011; Waltzer \& Dahl, in press). Insofar as students judge cheating as wrong, we would expect them to experience conflict around their decisions not to report. The present research measured students' evaluations and reasoning about reporting-including whether they do not care about cheating - and assessed whether the provided reasons would influence others' decisions to report.

\section{The Present Research}

To address the apparent tension between students' disapproval of cheating and their resistance to reporting it, the present research investigated college students' reasoning about reporting a hypothetical peer's act of misconduct. To extend prior work, we used betweensubjects (Study 1) and within-subjects (Study 2) comparisons to examine responses to plagiarism separately from other forms of cheating.

In Study 1, we conducted structured interviews with undergraduate students about their decisions to report a hypothetical peer's act of plagiarism or cheating. Students first made a decision about whether they would report, and then explained why. In doing so, we were able to measure a large number of students' considerations without constraining their response options, allowing us to identify barriers that students naturally consider in deciding to report. We hypothesized that many students would decide against reporting, but these decisions would rarely be due to a lack of concern about cheating. Instead, we 
expected students' reasoning about these decisions would be marked by difficulties, as evidenced by conflicting statements, lack of information about school policy, and spontaneous mentions of alternatives to reporting.

Study 2 provided an experimental test of the reasons that participants expressed in Study 1 by varying these reasons across hypothetical vignettes in an online survey. This within-subject design offered increased statistical power and an experimental test of the situational features that appeared to guide students' decisions in Study 1. We expected decisions about reporting to vary across scenarios, demonstrating a link between students' endorsed reasons and hypothetical decisions. Specifically, we expected that factors students raised against reporting in Study 1 would reduce decisions to report in Study 2, and that factors raised in favor of reporting in Study 1 would increase decisions to report in Study 2.

In both studies, participants were undergraduate students attending a large public university in the Western United States. Students were recruited through a university subject pool and given course credit for participation, in accordance with the university's Institutional Review Board (IRB) policy (UCSC IRB \#HS2549). The research procedures for both studies were approved by the university's IRB.

The university in which this research was conducted is a non-honor code secular research university. Although the university does not have an honor code policy, the academic policy does urge students to report witnessed acts of cheating. It states that: "Students need to avoid academic misconduct themselves and are enjoined to report any cases of academic misconduct that are known to them. Students making such reports may maintain anonymity." (UCSC Division of Undergraduate Education, 2019).

\section{Study 1}

\section{Method}

Further methodological details are included in the Supplementary Online Materials (SOM). The SOM, anonymized data, analysis scripts, and high-resolution versions of the visuals are all publicly available on the Open Science Framework (https://osf.io/fngex/).

\section{Participants}

Participants were 141 undergraduate students (93 women, 43 men, 3 non-binary, and 2 people not reporting a gender; $M_{\text {age }}=19.76$ years; $\left.S D_{\text {age }}=1.76\right)$. Most participants $(80 \%)$ were born in the United States, and nearly half (46\%) were first-generation college students.

\section{Procedure}

Students participated in an in-lab, audio-recorded structured interview. To reduce potential effects of social desirability, the interviewer explained that the study was for psychological research and that it was confidential and completely separate from university administration. Participants were assured that there were no right or wrong answers, and that the researchers just wanted to understand their opinions. Using similar methods, participants in previous studies have been comfortable and fully willing to share their thoughts on the 
topic of academic cheating with us (Waltzer et al., 2018; Waltzer \& Dahl, in press). Audio recordings were masked, transcribed, and then deleted; participants' responses were stored without any identifiable information, in accordance with university IRB policy.

In a between-subjects design, participants were asked about whether they would report a hypothetical peer's act of either plagiarism (plagiarism condition, $n=71$ ) or other cheating (other cheating condition, $n=70$ ). The interviewer asked the following question: "If you knew that someone was engaging in [plagiarism/cheating], would you report it to anyone?" Participants were then asked to justify their decision (“Why?").

\section{Data Coding and Analysis}

Participants' responses, which were transcribed from audio recordings, were separated into individual statements for coding. Two coders independently classified statements based on coding schemes for decisions, references to school policy, alternative actions, and type of concern (see Table 1). These categorization schemes were developed through a mix of bottom-up and top-down approaches. Members of the research team reviewed a subset of the data to deductively generate categories that captured common types of responses (bottomup approach). Meanwhile, theoretically-relevant categories (e.g., lack of care) were also added (top-down approach). Because statements about not caring were too rare to be analyzed on their own (only mentioned by 5 participants), they were included in the evaluation of act category (type of concern, Table 1). Reliability was assessed by computing Cohen's kappa scores ( $\kappa)$ for both coders' categorization of a random subset of the data (20\% of all responses) (McHugh, 2012).

Applying the categorization schemes to all open-ended responses allowed for the data to be treated as fully quantitative: Each statement was assigned a number for each category $(1=$ present, $0=$ absent $)$. Data were then analyzed using generalized linear models (McCullagh \& Nelder, 1989). Models included fixed effects of condition (plagiarism vs. other cheating) and decision to report. Models used logistic link functions and binomial error distributions, and hypotheses were tested using likelihood ratio tests.

\section{Results}

Below, we report key findings on students' decisions about whether to report, difficulties in their decision-making, and the concerns students raised. Additional analyses are reported in the SOM (Supplementary Online Materials, https://osf.io/fngex/).

\section{Overall Decisions About Whether to Report}

Overall, $48 \%$ of participants said they would not report, $40 \%$ said their decision would depend on some factor, and $11 \%$ said they would report. Participants' decisions about whether to report did not differ by condition (plagiarism vs. other cheating), $D \mathrm{~s}(1)<0.35$, ps $>.559$.

\section{Conflict and Informational Assumptions in Decisions About Whether to Report}

Forty-nine percent of participants made statements both for and against reporting. Many participants expressed ignorance/rejection of school policies (e.g., "I have no idea how I would go about reporting it," 43\%) or made ambiguous statements (e.g., "The teacher's 


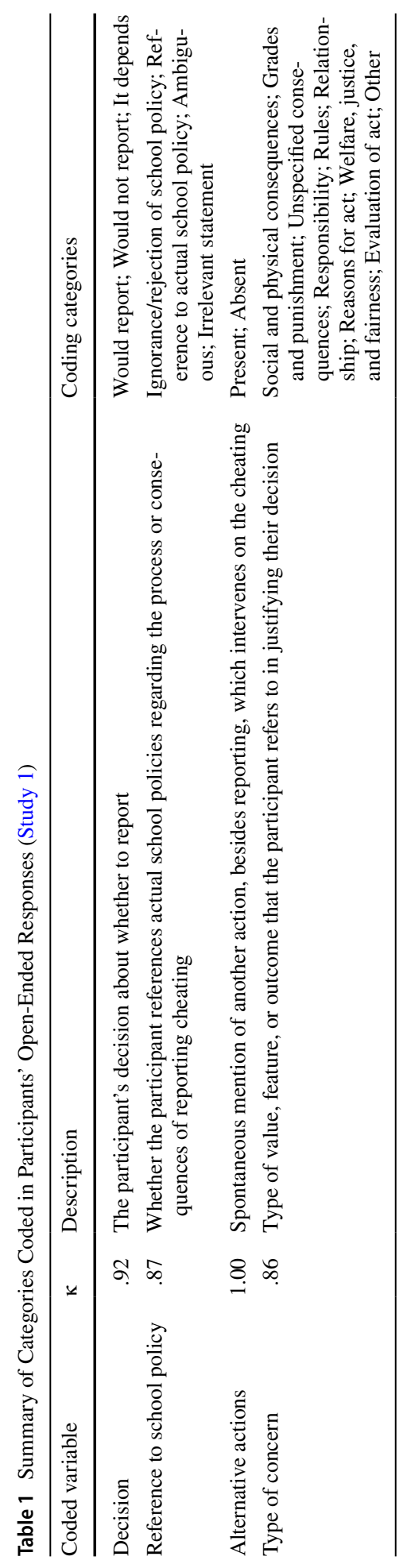


Table 2 Frequency of References to School Policies Based on Decision to Report (Study 1)

\begin{tabular}{llll}
\hline Decision to report & $\begin{array}{l}\text { Igno- } \\
\text { rance/ } \\
\text { rejection }\end{array}$ & $\begin{array}{l}\text { Ambiguous } \\
\text { statements }\end{array}$ & $\begin{array}{l}\text { Referenced } \\
\text { school policy }\end{array}$ \\
\hline Would not report $(n=68)$ & $49 \%$ & $63 \%$ & $22 \%$ \\
Depends $(n=57)$ & $46 \%$ & $74 \%$ & $25 \%$ \\
Would report $(n=16)$ & $6 \%$ & $19 \%$ & $62 \%$ \\
\hline
\end{tabular}

probably going to catch them," 62\%) that hinted at confusion about or misinterpretation of school policies. Only $28 \%$ referenced actual policy (e.g., "Because it [plagiarism] is against the rules"). Without being prompted, $30 \%$ of participants spontaneously offered an alternative course of action (e.g., "I would still tell them they probably shouldn't do that and try to guilt them into stopping"). None of the above response categories varied by condition, $D s(1)<2.03, p s>.155$.

Students' references to school policy (ignorance/rejection, reference to actual policy, or ambiguous) varied as a function of their decision about whether to report, $D \mathrm{~s}(2)>9.81, p \mathrm{~s}$ $<.008$. Post-hoc Wald tests revealed that participants who decided to report made more references to actual policy and had lower rates of ignorance/rejection and ambiguous statements, compared to those who said it depends or decided to not report (Table 2), $p$ s <.007.

\section{Reasoning About Whether to Report}

Most participants (65\%) raised multiple types of concerns when reasoning about whether to report $\left(M_{\text {overall }}=2.35\right.$ concerns $)$. Participants who said it depends provided more reasons than those who would report or would not report, $p s<.001$ (Table 3 ).

Figure 1 summarizes reasons for and against reporting. The most common reasons against reporting were concerns about responsibility (e.g., "it's not my job to point people out," 35\%), consequences (unspecified consequences: $27 \%$; grades and punishment: $24 \%$; social and physical consequences: $21 \%$ ), and act evaluations (e.g., "I feel like cheating isn't that bad," 21\%). The most common reasons for reporting were act evaluations (28\%) and welfare, justice, and fairness concerns (e.g., "I feel like it's wrong and dishonest and unfair to a lot of people," 16\%).

\section{Discussion}

Study 1 indicated that students were highly conflicted about whether to report plagiarism and other forms of cheating. Most participants gave reasons both for and against reporting, and almost a third of participants spontaneously offered alternative courses of action besides

Table 3 Average Number of Types of Concerns Raised to Justify Decision of Whether to Report (Study 1)

\begin{tabular}{lll}
\hline & $\begin{array}{l}\text { Average \# reasons } \\
\text { against reporting }\end{array}$ & $\begin{array}{l}\text { Average \# } \\
\text { reasons } \\
\text { for reporting }\end{array}$ \\
\hline Would not report $(n=68)$ & 1.76 & 0.19 \\
Depends $(n=57)$ & 1.95 & 1.58 \\
Would report $(n=16)$ & 0.06 & 1.56 \\
\hline
\end{tabular}




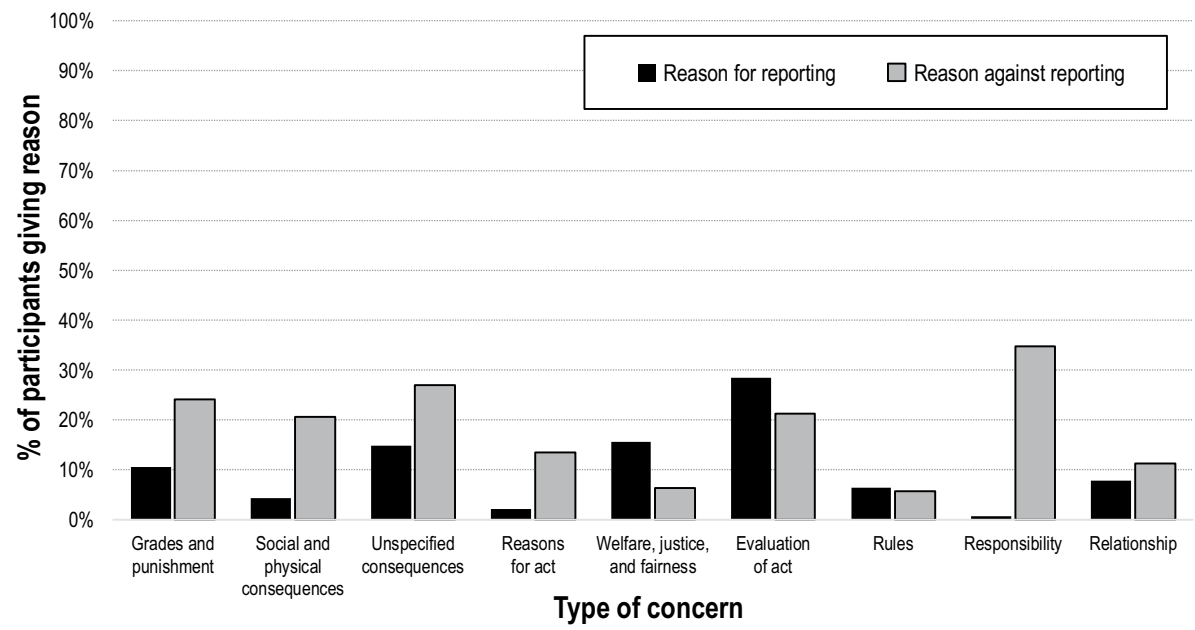

Fig. 1 Frequency of concerns raised by participants as reasons for or against reporting (Study 1)

reporting. Moreover, many students indicated beliefs that did not align with their school's policies about the process or consequences of reporting. The fact that students who opted against reporting expressed more confusion or ignorance compared to those who would report implies that inaccurate or incomplete information can guide students away from reporting, highlighting possible areas for educational intervention.

There were no significant differences between participants who were interviewed about plagiarism and those who were interviewed about other forms of cheating (see General Discussion). To further test for potential differences, Study 2 compared decisions about plagiarism and other forms of cheating across multiple scenarios in a within-subjects design.

The concerns expressed by participants (e.g., about responsibility, severity of the act, and consequences) suggested several factors that may guide students' decisions about whether to report. Still, the design of Study 1 prevented us from concluding that these factors did in fact guide students' decisions. To examine the link between reasoning and prospective actions more closely, Study 2 prompted students to make decisions about reporting across situations that differed in the presence of the concerns expressed in Study 1. For instance, some participants reasoned they would be more inclined to report if the act of cheating impacted their grades (e.g., "I'd be pissed off if I get a worse grade, below average, because someone else is cheating"); in Study 2, this concern was manipulated in the scenario, "Imagine you know that someone is cheating and in doing so they negatively affect the grades of you and your classmates" (for a similar approach, see Dahl et al., 2018). Using this design, Study 2 allowed for an experimental test of whether the factors referenced by participants in Study 1 mattered for judgments about reporting cheating. Study 2 adopted a within-subjects design to increase statistical power.

We expected open-ended responses in Study 2 to follow similar patterns as those in Study 1, reflecting conflicting concerns about whether to report. To further measure conflict, participants in Study 2 were asked whether they should report in addition to whether they would report. We hypothesized most students would say that they should report but also that they would not do so. We expected cross-situational variability in decisions to report. Specifically, we hypothesized that situations based on reasons in favor of reporting would yield more decisions to report, and vice versa for situations based on reasons against reporting. 


\section{Study 2}

\section{Method}

\section{Participants}

We recruited 103 undergraduate students (76 women, 24 men, 1 other response, and 2 people not reporting a gender; $M_{\text {age }}=20.21 ; S D_{\text {age }}=1.52$ ) to participate in an online survey.

\section{Materials and Procedure}

Participants responded to a 30-minute online survey administered through Qualtrics. The survey was designed to validate and build on the findings from Study 1. In the first section of the survey, to validate findings from Study 1, participants were asked the same general question as in Study 1 (i.e., "If you knew that someone was engaging in [plagiarism/cheating], would you report it to anyone?"), selecting either would report or would not report. They also rated their likelihood of reporting (sliding scale from $0=$ "Extremely unlikely" to $10=$ "Extremely likely"), chose whether they should or should not report, and then provided an open-ended explanation for their responses. All participants answered these questions about both plagiarism and cheating (within-subjects design).

This survey also built on Study 1 by using the findings from participants' open-ended responses to develop scenarios that were relevant to students' concerns. In the second section of the survey, participants responded to several modified situations that were created using the features that participants referenced in Study 1 (e.g., "Imagine you know that someone is cheating, and in doing so they receive a better grade than those who worked honestly," see Appendix). All scenarios were presented to each participant in randomized order. For each situation, all participants provided three responses: they made a dichotomous choice (report or do not report), rated their likelihood of reporting (sliding scale from $0=$ "Extremely unlikely" to $10=$ "Extremely likely"), and rated how good or bad it would be to report (from $0=$ "Really bad" to $10=$ "Really good").

\section{Data Coding}

As in Study 1, participants' open-ended explanations were coded using the schemes: decision $(\kappa=.97)$, reference to school policy $(\kappa=.93)$, alternative actions $(\kappa=1.00)$, and type of concern $(\kappa=.95)$.

\section{Data Analysis}

Analyses of condition effects (plagiarism vs. other cheating) on dichotomous dependent variables were conducted using McNemar's method and exact binomial tests for testing hypotheses. For all other analyses, data were analyzed using generalized linear mixed models with random intercepts for participants and fixed effects of decision about whether to report (Hox, 2010). Models for dichotomous dependent variables used logistic link functions and binomial error distributions. For analyses using continuous dependent variables, models used identity link functions, normal error distributions, and full maximum likelihood estimation. Hypotheses were tested using likelihood ratio tests. 
Table 4 Frequency of References to School Policies Based on Decision to Report (Study 2)

\begin{tabular}{llll}
\hline & $\begin{array}{l}\text { Ignorance/ } \\
\text { rejection }\end{array}$ & $\begin{array}{l}\text { Ambiguous } \\
\text { statements }\end{array}$ & $\begin{array}{l}\text { Referenced } \\
\text { school } \\
\text { policy }\end{array}$ \\
\hline Would not report $(n=141)$ & $45 \%$ & $47 \%$ & $24 \%$ \\
Would report $(n=55)$ & $2 \%$ & $11 \%$ & $40 \%$ \\
\hline
\end{tabular}

Further methodological details are included in the SOM (https://osf.io/fngex/).

\section{Results}

Key findings related to the central research questions are reported here. Additional analyses are reported in the SOM.

\section{General Questions About Reporting}

Overall Decisions About Whether to Report In most of the general cases (55\%), students said that they should report but would not report, evidencing conflict. Students said they should report and would report in $25 \%$ of cases. They said they should not and would not report in $18 \%$ of cases. Their general decisions to report did not differ between plagiarism and other cheating, $p \mathrm{~s}>.249$. The mean likelihood of reporting across these cases $\left(M_{\text {likelihood }}=4.06, S D=2.48\right)$ was close to the midpoint $(5.00)$, suggesting that participants tended to experience some conflict about whether to report.

Conflict, Informational Assumptions, and Reasoning About Whether to Report As in Study 1, participants made statements both for and against reporting in several cases (28\%). In line with the idea that students are concerned about cheating, this conflict was more likely among participants who said they would not report (35\%) than those who said they would $(7 \%), D(1)=23.13, p<.001$. Unlike in Study 1 , few participants spontaneously mentioned alternative actions ( $3 \%$ of cases) ${ }^{1}$. Similar to Study 1, participants often expressed ignorance/ rejection of school policy (33\%) and made ambiguous statements about policies (37\%). Participants were more likely to express ignorance or rejection of policies or make ambiguous statements when they decided not to report, $D \mathrm{~s}(1)>22.71, p \mathrm{~s}<.001$ (Table 4). There were no significant effects of condition (plagiarism vs. other cheating) on participants' mentions of both courses of action, alternative actions, or school policies, $p$ s $>.115$.

On average, participants reasoned about more concerns when they said they would not report (1.70) than when they said they would (1.22), $D(1)=8.81, p=.003$. As in Study 1 , participants often referenced their lack of responsibility (32\% of cases) and various consequences (grades and punishment: 10\%; social and physical: 16\%; unspecified: $7 \%$ ) as reasons against reporting, and typically referenced welfare, justice, and fairness (28\%), act evaluations (13\%), and rules (13\%) as reasons for reporting.

\footnotetext{
1 In a follow-up online survey with a separate sample of undergraduates $(N=40)$, we directly prompted for alternative actions. As expected, most participants (73\%) responded yes to the question "Would you consider taking any alternative actions instead of reporting a student for cheating or plagiarizing?" In their open-ended explanations, most $(90 \%)$ said they would talk to the person (e.g., seeking to understand why they cheated, warning them of consequences, or offering assistance to avoid cheating).
} 


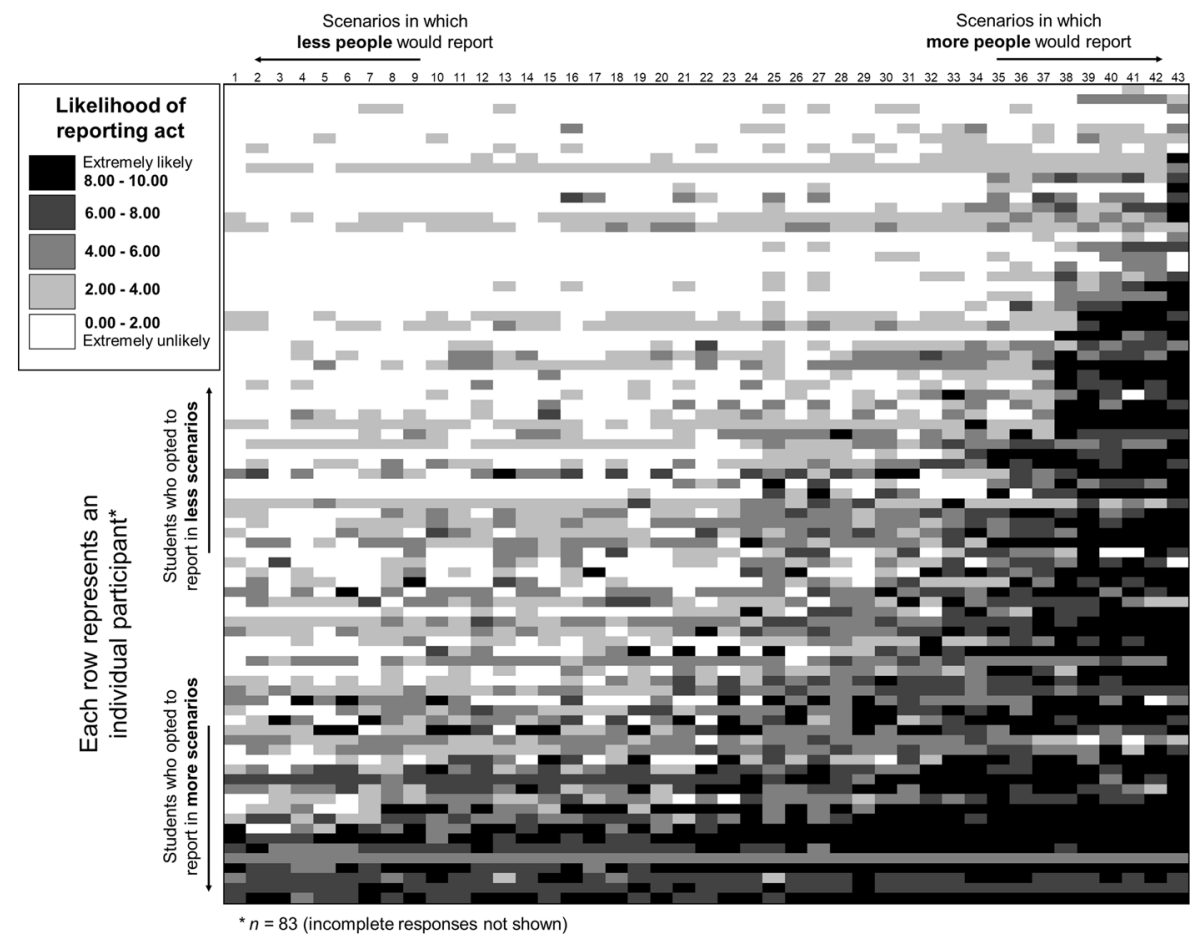

Fig. 2 Case graph of variability in decisions across situations (Study 2)

\section{Questions About Reporting Across Situations}

Variability Across Situations Participants' decisions varied substantially across scenarios. Only $11 \%$ of participants said they would not report in any case, and only $1 \%$ said they would report in every case. At the same time, the average likelihood of reporting varied substantially between participants. Illustrating both within- and between-participant variability, Fig. 2 visualizes case-by-base responses for each participant.

When comparing scenarios that had both a plagiarizing and a cheating version (see Appendix), the type of act (plagiarism vs. other cheating) did not significantly predict decisions, $D(1)=0.08, p=.783$.

Effect of Manipulated Features on Decisions to Report As expected, scenarios that were based on the features mentioned in Study 1 as motivations in favor of reporting did yield more decisions to report $(48 \%, D[1]=61.12, p<.001)$ and higher likelihood of reporting $\left(M_{\text {likelihood }}=5.12, D[1]=57.46, p<.001\right)$ compared to the general case $(28 \%$, $\left.M_{\text {likelihood }}=4.06\right)$. Reflecting the importance of contextual features, some cases yielded broad agreement (e.g., 79\% of students would report when their own work was being plagiarized). The scenarios in which students were most willing to report were those in which the reporter had some personal stake in the situation (e.g., when the act of cheating would impact them directly). 
Fig. 3 Bubble plot depicting relation between evaluative rating and likelihood of reporting (Study 2). Larger bubbles indicate more responses. Students were more likely to report acts when they rated reporting in those situations more positively

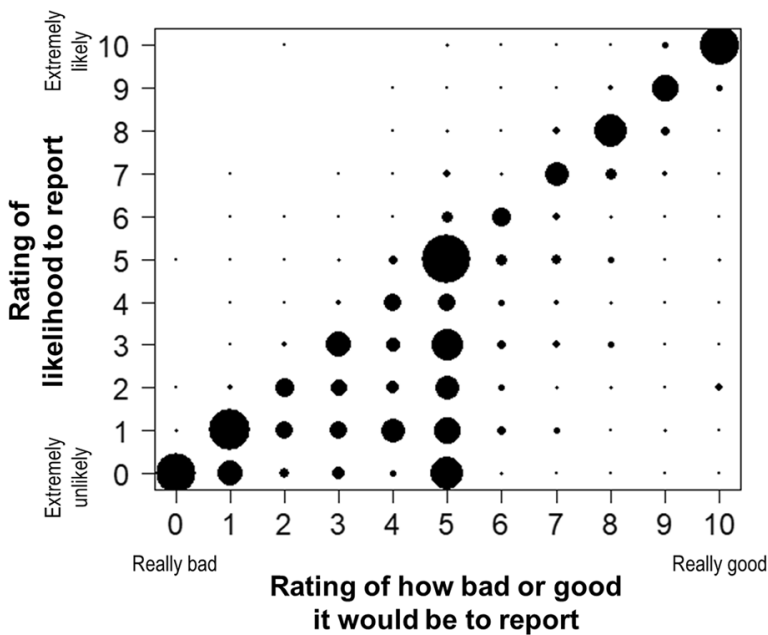

Additionally, as expected, scenarios based on motivations against reporting yielded less decisions to report (only $22 \%$ would report, $D[1]=4.23, p=.040$ ) and lower likelihood of reporting $\left(M_{\text {likelihood }}=3.17, D[1]=34.32, p<.001\right)$ compared to the general case. Again, some scenarios yielded broad agreement (e.g., only $11 \%$ of students would report cheating when they had to fill out paperwork and attend academic hearings). The scenarios in which students expressed the least willingness to report were those that involved extra work for the reporter, uncertainty surrounding the circumstances of cheating, or minor offenses (e.g., "plagiarizing just a few words or sentences").

Relation Between Evaluation of Reporting and Decision to Report There was a strong, positive correlation between participants' ratings of how good or bad it was to report and their rating of how likely they were to report in that situation, Pearson's $r=.72, D(1)=$ $2734.81, p<.001$. As suggested by Fig. 3, a substantial proportion of those who gave positive evaluations of reporting (above 5.00) nevertheless chose not to report (36\%, vs. $88 \%$ of those who gave negative evaluations of reporting). However, this does not mean that these participants' evaluations were unrelated to their intended decisions. Even within the cases for which participants gave positive evaluations of reporting, evaluations and intentions to report were positively correlated, $r=.46, D(1)=619.22, p<.001$ : Participants who gave less positive evaluations of reporting were also less likely to say they would report, compared to participants who gave more positive evaluations of reporting.

\section{Discussion}

As in Study 1, most participants in Study 2 generally decided against reporting, but nevertheless expressed conflict. Most believed they should report, and many made statements that supported both decisions. Decisions against reporting were rarely due to a lack of care: Only one participant said they did not care enough about cheating to report it.

Study 2 also showed that students' judgments about reporting of cheating are sensitive to the specific context of cheating acts. As hypothesized, the reasons students raised in favor of reporting (in Study 1) increased decisions to report (in Study 2), whereas 
reasons against reporting decreased rates of intended reporting. Further evidencing the link between reasoning and decisions, students' evaluations of reporting and decisions to report were strongly correlated.

\section{General Discussion}

Though most students care about academic integrity, they often decide against reporting their peers' acts of cheating. The present research suggested that students do care about integrity, contrasting with prior accounts that imply otherwise (Ariely, 2012; Bandura, 2016; McCabe, 1997; Sykes \& Matza, 1957; for a related argument, see Stuhmcke et al., 2016). The findings provided evidence for three factors that help explain why students refrain from reporting, despite their concerns for integrity: competing considerations, informational assumptions, and better alternatives. We discuss each of these points below.

\section{Students Balance Competing Considerations}

Both studies indicated that decisions about reporting are complex and involve competing considerations: Students believed the cheating was wrong, but simultaneously considered personal costs (e.g., reputational consequences) or moral concerns (e.g., ruining someone's academic career). Most participants raised multiple concerns when reasoning about whether to report (e.g., "I know that person is doing something wrong, but I don't want to be the reason someone gets in trouble"). This research further illustrates how many moral decisions involve weighing competing concerns (Nucci, 2004; Turiel \& Dahl, 2019). When these concerns call for diverging courses of action, a compromise must be made. Reasoning about whether to report cheating, like reasoning about other acts of intervention against wrongdoing, involves conflict (e.g., Latané \& Darley, 1970; Waytz et al., 2013).

\section{Students Make Varying Informational Assumptions}

Another factor in students' decisions was informational: Many students expressed ignorance about school policies, reporting procedures, consequences of reporting, the cheating student's actions, or the student's motivations for cheating. Consistent with prior research, students' beliefs and knowledge about institutional policies were related to their decisions (Ajzen et al., 2011; Jordan, 2001). Indeed, in real academic situations, students often lack complete information about what constitutes a violation or what the process of reporting entails. For example, many students have not read their school's academic misconduct policy (Gullifer \& Tyson, 2014).

\section{Students Perceive Better Alternatives to Reporting}

Study 1 showed that students often prefer alternative courses of action over reporting a peer's cheating to the teacher. Without being prompted, students spontaneously proposed alternative courses of action besides reporting or doing nothing (e.g., privately telling the student they are doing something wrong, helping the student complete the work without cheating). These alternative actions further evidence that students are often concerned with stopping cheating even when they decide not to report it. Fewer participants mentioned alternative actions in Study 2. A likely explanation is that Study 2 used online surveys, which tend to elicit shorter responses to open-ended questions than in-person interviews (Dahl et al., 2018). 


\section{Students Do Care About Integrity}

The present research provided abundant evidence that students are concerned with academic integrity. In both studies, many participants provided reasons in favor of reporting. In Study 2, there were several scenarios in which the majority chose to report. Most participants in Study 2 also believed they generally should report cheating (80\%). Even in the cases that students decided not to report, they expressed conflict and acknowledged reasons in favor of reporting (e.g., "Reporting a student who is cheating is probably the honest thing to do, however it's not my responsibility to worry about what other students are doing"). When students gave reasons against reporting, statements about not caring were exceedingly rare. Study 2 confirmed the influential role students' reasons had in guiding their decisions (Ajzen, 1985, 1988; Ajzen \& Fishbein, 2005; Dahl et al., 2018; Knafo et al., 2011; Schwartz, 2012; Turiel, 2003).

\section{Future Directions for Research}

This research revealed minimal differences between decisions about plagiarism and other forms of cheating. Although prior work has highlighted that it may be uniquely difficult for students to determine what constitutes plagiarism (Gullifer \& Tyson, 2014; Power, 2009; Stuhmcke et al., 2016), the present study removed this difficulty by describing the events presented to participants explicitly as plagiarism. In real academic situations, distinctions between plagiarism and other forms of cheating are characterized by details of the particular acts; when these nuances are stripped away, students may not distinguish plagiarism from other forms of cheating. It is likely that students' responses would have been different if the study had introduced uncertainty about whether the perceived event constituted plagiarism (Waltzer \& Dahl, in press). We expect, for instance, that students would be less likely to report an ambiguous case of plagiarism than a clear-cut case of a student hiring someone else to take a test. To address this concern, future research could use hypothetical vignettes depicting concrete examples of student actions (e.g., text from a student's submission) to better capture the uncertainties of identifying plagiarism in real academic situations (Childers \& Bruton, 2016; Roig, 1997, 2001; Waltzer \& Dahl, in press).

A second area for future research concerns the role of institutional factors (e.g., honor codes) and individual differences (e.g., personality traits). The present work provides a foundation for such future directions by identifying situational features and reasons for and against reporting that could interact with these factors. Building on prior research predicting institutional and individual differences in cheating as well as whistle-blowing (Kisamore et al., 2007; McCabe et al., 2012; Miller et al., 2007; Scrimpshire et al., 2017; Stone et al., 2009; Stone et al., 2012), future research could seek to predict whether some individuals are more likely to report specific acts of cheating than others.

Relations between judgments and actions have received a great deal of theoretical and empirical attention (Blasi, 1980; Thoma, 1994; Stephens, 2018; Turiel, 2003; Waltzer et al., 2019). Previous research has found that people's judgments and values largely guide their behaviors (Ajzen, 1985, 1988, 1991; Ajzen \& Fishbein, 2005; Knafo et al., 2011; Schwartz, 2012). However, in Study 2, most students (55\%) seemingly contradicted themselves by saying they should report but would not report. Students' open-ended justifications hint at a distinction between what is objectively right and what is personally required: Many said they felt, from an objective standpoint, that the act "ethically should be reported," but at the same time they personally felt it was "not [their] place" to report and feared the "stigma around 
reporting." Nevertheless, there was a strong positive correlation between evaluations and decisions about reporting $(r=.72)$. Future research can more closely examine the nature of students' judgments about what they "should" do to determine whether they see reporting as going beyond what is morally required (i.e., supererogatory; McNamara, 2011).

One limitation is that the present research did not directly assess students' personal experiences of observing cheating incidents and deciding whether to report in real life. In addition to students' predicted actions, it would be valuable to examine their actions in real situations (e.g., Ajzen, 1991; Mesmer-Magnus \& Viswesvaran, 2005; Woodzicka \& LaFrance, 2001). Predicted and actual decisions may sometimes differ because decisions about reporting occur in complicated situations with informational ambiguity, multiple competing considerations, and other intervening factors (e.g., perceived behavioral control; Ajzen, 1991). The relatively simple scenarios tested in the present research identified specific factors that mattered in students' decisions to report (e.g., personal involvement in the situation, severity of cheating act), which can be combined to capture the complexity of decisions in realistic situations. Building on methods that test decisions to report in experimental settings (Jenkel \& Haen, 2012; Yachison et al., 2018), future extensions of this research can investigate whether students' predictions align with their decisions in academic contexts.

\section{Conclusion}

Decisions about whether to report witnessed acts of cheating occur in complex situations, with incomplete information and conflicting considerations. Both studies indicated that decisions about whether to report are sensitive to features of the situation in which the cheating and reporting occurs. The findings have implications not only for scientific theories of socio-moral decision-making, but also for educators who seek to support academic integrity among students. Efforts to increase students' willingness to report would need to address the specific reasons and beliefs that discourage students from reporting. For example, to address uncertainty or ignorance of policies, educators could offer students clear information about the process and consequences of reporting (e.g., explicitly stating whether students are responsible for reporting). In addition, to change student decisions about reporting, educators could examine the concerns students have against reporting and adjust the assignment or classroom structure accordingly (e.g., increasing ease or anonymity of reporting).

\section{Appendix: Summary of Types of Situations Mentioned in Study 1 and Manipulated in Study 2}

To create stimuli for Study 2, participant statements in Study 1 were categorized based on the situational factors that they stated would influence their decision to report $(\kappa=1.00)$. Common factors included whether anyone was affected by the act, whether the cheater would receive an unfair grade, and whether it is the witness's business to get involved. See Table 5 for all percentages.

For additional details, full-size figures, and more visuals, see the SOM (https://osf.io/ fngex/). 


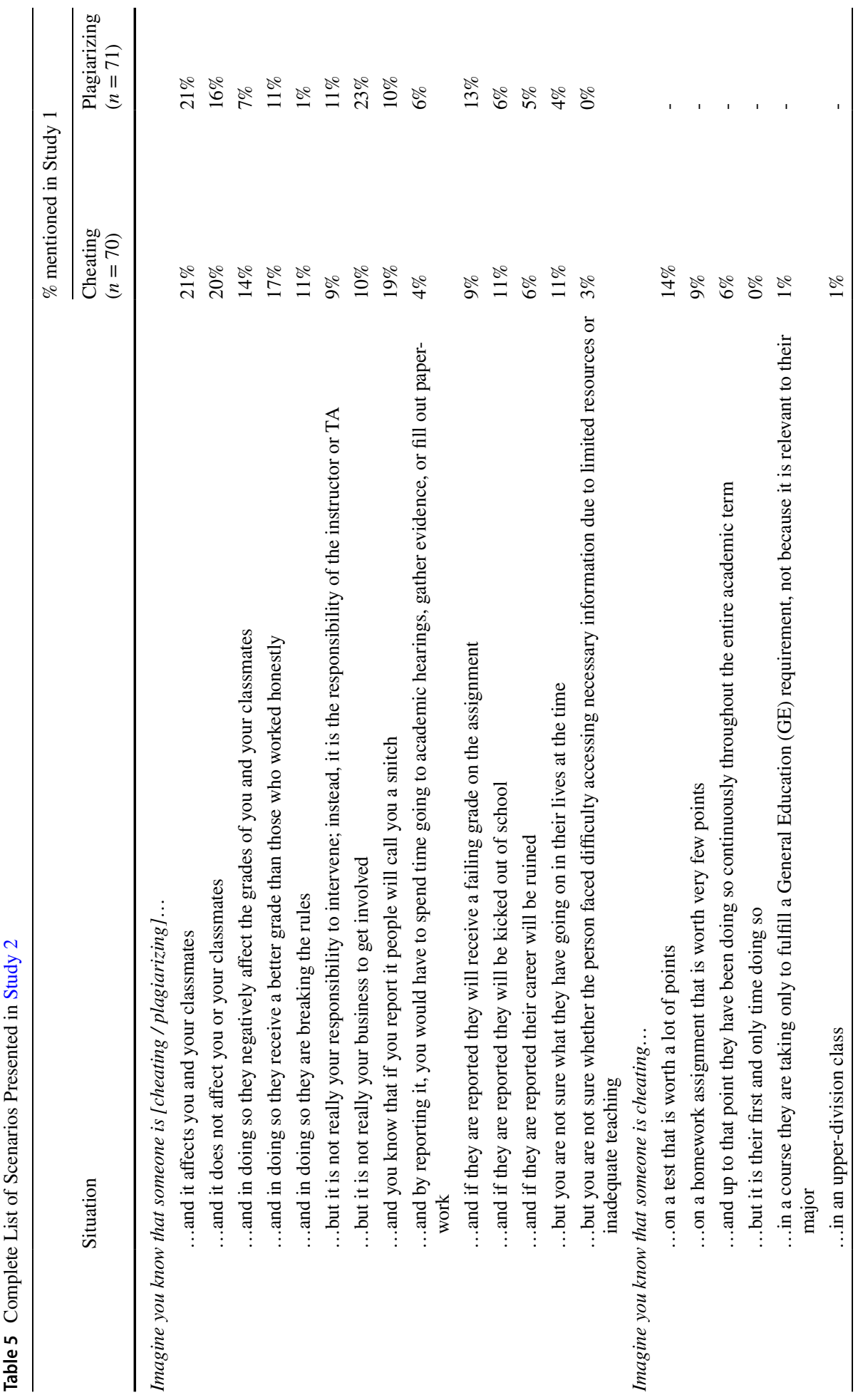




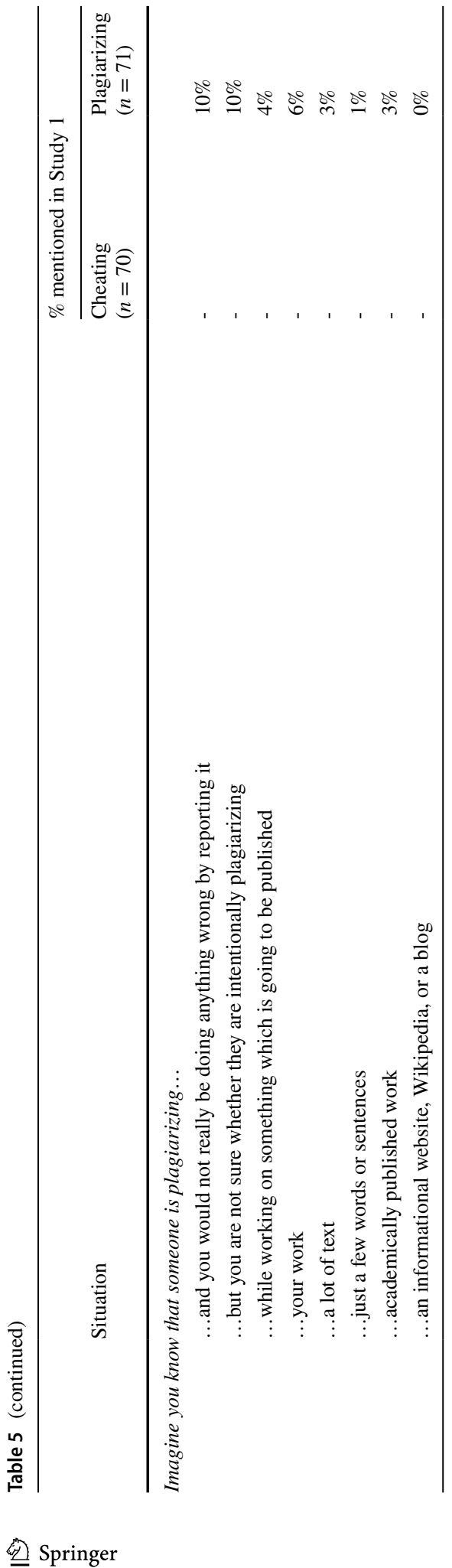


Supplementary Information The online version contains supplementary material available at https://doi. org/10.1007/s10805-021-09414-4.

Acknowledgments Thank you to the participants of this research and the Psychology Department at the University of California, Santa Cruz. We would like to thank Carmelle Bareket-Shavit and Max WechslerAzen for their assistance with study piloting, data collection, transcribing, and data coding. In addition, we would like to thank members of the Academic Orientations Project at the University of California, Santa Cruz for providing input on the research methods, data interpretation, and earlier drafts of the manuscript. We also thank Benjamin Storm and members of the Developmental Moral Psychology Lab for comments on a previous version of the manuscript.

Authors' Contributions Talia Waltzer designed the methods and materials, collected data, coded qualitative data, wrote data loading and analysis scripts, and prepared the manuscript. Arvid Samuelson contributed to study design, data collection, transcribing, coding of qualitative data, descriptive data analyses, and preparation of the manuscript, in fulfillment of an undergraduate Senior Thesis Project in the Department of Psychology at the University of California, Santa Cruz. Audun Dahl supervised the project, contributing to study design, data analysis, and preparation of the manuscript.

Funding There are no sources of funding to report for this research.

Availability of Data and Material The materials used to conduct the research, and the data supporting the findings of the research, are available on the Open Science Framework: https://osf.io/fngex/.

Code Availability Data cleaning and analysis was conducted in R. The R scripts for the research are available on the Open Science Framework: https://osf.io/fngex/.

\section{Declarations}

Conflicts of Interest The authors have no potential conflicts of interest to report.

Open Access This article is licensed under a Creative Commons Attribution 4.0 International License, which permits use, sharing, adaptation, distribution and reproduction in any medium or format, as long as you give appropriate credit to the original author(s) and the source, provide a link to the Creative Commons licence, and indicate if changes were made. The images or other third party material in this article are included in the article's Creative Commons licence, unless indicated otherwise in a credit line to the material. If material is not included in the article's Creative Commons licence and your intended use is not permitted by statutory regulation or exceeds the permitted use, you will need to obtain permission directly from the copyright holder. To view a copy of this licence, visit http://creativecommons.org/licenses/by/4.0/.

\section{References}

Ajzen, I. (1985). From intentions to action: A theory of planned behavior. In J. Kuhl \& J. Beckman (Eds.), Action control: From cognitions to behaviors (pp. 11-39). Springer.

Ajzen, I. (1988). Attitudes, personality, and behavior. The Dorsey Press.

Ajzen, I. (1991). The theory of planned behavior. Organizational Behavior and Human Decision Processes, 50(2), 179-211.

Ajzen, I., \& Fishbein, M. (2005). The influence of attitudes on behavior. In D. Albarracín, B. T. Johnson, \& M. P. Zanna (Eds.), The handbook of attitudes (pp. 173-221). Erlbaum.

Ajzen, I., Joyce, N., Sheikh, S., \& Cote, N. G. (2011). Knowledge and the prediction of behavior: The role of information accuracy in the theory of planned behavior. Basic and Applied Social Psychology, 33, $101-117$.

Ariely, D. (2012). The honest truth about dishonesty: How we lie to everyone - especially ourselves. Harper Collins.

Arnold, R., Martin, B. N., \& Bigby, L. (2007). Is there a relationship between honor codes and academic dishonesty? Journal of College and Character, 8, 1-20. 
Baird, J. S. (1980). Current trends in college cheating. Psychology in the Schools, 17, 515-522.

Bandura, A. (2016). Moral disengagement: How people do harm and live with themselves. Macmillan Higher Education.

Barnhardt, B. (2016). The "epidemic" of cheating depends on its definition: A critique of inferring the moral quality of "cheating in any form". Ethics \& Behavior, 26(4), 330-343.

Blasi, A. (1980). Bridging moral cognition and moral action: A critical review of the literature. Psychological Bulletin, 88, 1-45.

Brown, D. L. (2002). Cheating must be okay - everybody does it! Nurse Educator, 27, 6-8. https://doi.org/ 10.1097/00006223-200201000-00010

Burrus, R. T., Jones, A. T., Sackley, B., \& Walker, M. (2013). It's the students, stupid: How perceptions of student reporting impact cheating. The American Economist, 58, 51-59.

Burton, B. K., \& Near, J. P. (1995). Estimating the incidence of wrongdoing and whistle-blowing: Results of a study using randomized response technique. Journal of Business Ethics, 14(1), 17-30.

Childers, D., \& Bruton, S. (2016). "Should it be considered plagiarism?" Student perceptions of complex citation issues. Journal of Academic Ethics, 14, 1-17.

Cizek, G. J. (2003). Detecting and preventing classroom cheating: Promoting integrity in assessment. Corwin Press.

Dahl, A., Gingo, M., Uttich, K., \& Turiel, E. (2018). Moral reasoning about human welfare in adolescents and adults: Judging conflicts involving sacrificing and saving lives. Monographs of the Society for Research in Child Development, Serial No. 330(83), 1-109.

Darley, J. M., \& Latané, B. (1968). Bystander intervention in emergencies: Diffusion of responsibility. Journal of Personality and Social Psychology, 8, 377-383.

Davis, S. F., Grover, C. A., Becker, A. H., \& McGregor, L. N. (1992). Academic dishonesty: Prevalence, determinants, techniques, and punishments. Teaching of Psychology, 11, 16-20.

Dozier, J. B., \& Miceli, M. P. (1985). Potential predictors of whistle-blowing: A prosocial behavior perspective. The Academy of Management Review, 10, 823-836.

Fehr, E., \& Fischbacher, U. (2003). The nature of human altruism. Nature, 425, 785-791.

Fehr, E., \& Fischbacher, U. (2004). Third party punishments and social norms. Evolution and Human Behavior, 25, 63-87.

Genereux, R. L., \& McLeod, B. A. (1995). Circumstances surrounding cheating: A questionnaire study of college students. Research in Higher Education, 36, 687-704.

Gullifer, J. M., \& Tyson, G. A. (2014). Who has read the policy on plagiarism? Unpacking students' understanding of plagiarism. Studies in Higher Education, 39, 1202-1218.

Harding, T. S., Mayhew, M. J., Finelli, C. J., \& Carpenter, D. D. (2007). The theory of planned behavior as a model of academic dishonesty in engineering and humanities undergraduates. Ethics \& Behavior, 17, 255-279.

Henrich, J., McElreath, R., Barr, A., Ensminger, J., Barrett, C., Bolyanatz, A., \& Ziker, J. (2006). Costly punishment across human societies. Science, 23, 1767-1770.

Houston, J. P. (1976). The assessment and prevention of answer copying on undergraduate multiple-choice examinations. Research in Higher Education, 5, 301-311.

Hox, J. (2010). Multilevel analysis: Techniques and applications (2nd ed.). Routledge.

Jackson, D., Hickman, L. D., Hutchinson, M., Andrew, S., Smith, J., Potgieter, I., Cleary, M., \& Peters, K. (2014). Whistleblowing: An integrative literature review of data-based studies involving nurses. Contemporary Nurse, 48, 240-252.

Jendrek, M. P. (1992). Student reactions to academic dishonesty. Journal of College Student Development, $33,260-273$.

Jenkel, I., \& Haen, J. J. (2012). Influences on students' decisions to report cheating: A laboratory experiment. Journal of Academic Ethics, 10, 123-136. https://doi.org/10.1007/s10805-012-9154-7

Jensen, L. A., Arnett, J. J., Feldman, S. S., \& Cauffman, E. (2002). It's wrong, but everybody does it: Academic dishonesty among high school and college students. Contemporary Educational Psychology, 27, 209-228.

Jordan, A. E. (2001). College student cheating: The role of motivation, perceived norms, attitudes, and knowledge of institutional policy. Ethics \& Behavior, 11, 233-247. https://doi.org/10.1207/s15327019eb1103_3

Keeney, R. L., \& Raiffa, H. (1976). Decisions with multiple objects: Preferences and value tradeoffs. Wiley.

Kisamore, J. L., Stone, T. H., \& Jawahar, I. M. (2007). Academic integrity: The relationship between individual and situational factors on misconduct contemplations. Journal of Business Ethics, 75(4), 381-394.

Knafo, A., Roccas, S., \& Sagiv, L. (2011). The value of values in cross-cultural research: A special issue in honor of Shalom Schwartz. Journal of Cross-Cultural Psychology, 42, 178-185. 
Kohlberg, L. (1971). From is to ought: How to commit the naturalistic fallacy and get away with it in the study of moral development. In T. Mischel (Ed.), Cognitive development and epistemology (pp. 151235). Academic Press.

Latané, B., \& Darley, J. M. (1970). The unresponsive bystander: Why doesn't he help? Appleton Century Crofts.

Latané, B., \& Nida, S. (1981). Ten years of research on group size and helping. Psychological Bulletin, 89, $308-324$.

Levine, T. R., Kim, R. K., \& Hamel, L. R. (2010). People lie for a reason: Three experiments documenting the principle of veracity. Communication Research Reports, 27(4), 271-285. https://doi.org/10.1080/ 08824096.2010 .496334

Lim, V. K., \& See, S. K. (2001). Attitudes toward, and intentions to report, academic cheating among students in Singapore. Ethics \& Behavior, 11, 261-274.

McCabe, D. L. (1997). Classroom cheating among natural science and engineering majors. Science and Engineering Ethics, 3, 433-445.

McCabe, D. L., \& Treviño, L. K. (1993). Academic dishonesty: Honor codes and other contextual influences. The Journal of Higher Education, 60, 522-538.

McCabe, D. L., Butterfield, K. D., \& Treviño, L. K. (2012). Cheating in college: Why students do it and what educators can do about it. The Johns Hopkins University Press.

McCabe, D. L., Treviño, L. K., \& Butterfield, K. D. (2001). Dishonesty in academic environments: The influence of peer reporting requirements. The Journal of Higher Education, 72, 29-45.

McCullagh, P., \& Nelder, J. A. (1989). Generalized linear models (2nd ed.). Chapman and Hall.

McHugh, M. L. (2012). Interrater reliability: The kappa statistic. Biochemia Medica, 22, 276-282.

McNamara, P. (2011). Supererogation, inside and out: Toward an adequate scheme for common sense morality. In M. Timmons (Ed.), Oxford studies in normative ethics (Vol. 1, pp. 202-235). Oxford University Press.

Mesmer-Magnus, J. R., \& Viswesvaran, C. (2005). Whistleblowing in organizations: An examination of correlates of whistleblowing intentions, actions, and retaliation. Journal of Business Ethics, 62, 277-297.

Miller, A., Shoptaugh, C., \& Wooldridge, J. (2011). Reasons not to cheat, academic-integrity responsibility, and frequency of cheating. The Journal of Experimental Education, 79(2), 169-184.

Miller, A. D., Murdock, T. B., Anderman, E. M., \& Poindexter, A. L. (2007). Who are all these cheaters? Characteristics of academically dishonest students. In E. M. Anderman \& T. B. Murdock (Eds.), Psychology of academic cheating (pp. 9-32). Elsevier Academic Press.

Moss, S. A., White, B., \& Lee, J. (2018). A systematic review into the psychological causes and correlates of plagiarism. Ethics and Behavior, 28(4), 261-283. https://doi.org/10.1080/10508422.2017.1341837

Murdock, T. B., Stephens, J. M., \& Grotewiel, M. M. (2016). Student dishonesty in the face of assessment: Who, why, and what we can do about it. In G. T. Brown \& L. R. Harris (Eds.), Handbook of human factors and social conditions in assessment (pp. 186-203). Routledge.

Near, J. P., \& Miceli, M. P. (1985). Organizational dissidence: The case of whistle-blowing. Journal of Business Ethics, 4, 1-16.

Neff, K. D., \& Helwig, C. C. (2002). A constructivist approach to understanding the development of reasoning about rights and authority within cultural contexts. Cognitive Development, 17, 1429-1450.

Nitsch, D., Baetz, M., \& Hughes, J. C. (2005). Why code of conduct violations go unreported: A conceptual framework to guide intervention and future research. Journal of Business Ethics, 57, 327-341.

Nucci, L. P. (2004). Reflections on the moral self construct. In D. Lapsley \& N. Narvaez (Eds.), Moral development, self, and identity (pp. 111-132). Erlbaum.

Nuss, E. M. (1984). Academic integrity: Comparing faculty and student attitudes. Improving College and University Teaching, 32(3), 140-144.

Park, C. (2003). In other (people's) words: Plagiarism by university students-literature and lessons. Assessment \& Evaluation in Higher Education, 28, 471-488.

Philpot, R., Liebst, L. S., Levine, M., Bernasco, W., \& Lindegaard, M. R. (2020). Would I be helped? Cross-national CCTV footage shows that intervention is the norm in public conflicts. American Psychologist, 75(1), 66-75. https://doi.org/10.1037/amp0000469

Pennycook, A. (1996). Borrowing others' words: Text, ownership, memory, and plagiarism. TESOL Quarterly, 30, 201-230.

Power, L. G. (2009). University students' perceptions of plagiarism. The Journal of Higher Education, $80,643-662$.

Pupovac, V., Popović, S., \& Blažina, V. (2019). What prevents students from reporting academic misconduct? A survey of Croatian students. Journal of Academic Ethics, 17, 389-400. https://doi.org/ $10.1007 / \mathrm{s} 10805-019-09341-5$ 
Rennie, C. S., \& Crosby, R. J. (2002). Students' perceptions of whistleblowing: Implications for selfregulation. Medical Education, 36, 173-179.

Roig, M. (1997). Can undergraduate students determine whether text has been plagiarized? The Psychological Record, 47, 113-122.

Roig, M. (2001). Plagiarism and paraphrasing criteria of college and university professors. Ethics \& Behavior, 11, 307-323.

Rundle, K., Curtis, G. J., \& Clare, J. (2019). Why students do not engage in contract cheating. Frontiers in Psychology, 10, 2229.

Schwartz, B., Tatum, H., \& Hageman, M. (2013). Undergraduate perceptions of and responses to academic dishonesty: The impact of honor codes. Ethics \& Behavior, 23, 463-476.

Schwartz, S. H. (2012). An overview of the Schwartz theory of basic values. Online Readings in Psychology and Culture, 2, 1-20. https://doi.org/10.9707/2307-0919.1116

Scrimpshire, A., Stone, T. H., Kisamore, J. L., \& Jawahar, I. M. (2017). Do birds of a feather cheat together? How personality and relationships affect student cheating. Journal of Academic Ethics, 15(1), 1-22. https://doi.org/10.1007/s10805-016-9267-5

Semerci, C. (2006). The opinions of medicine faculty students regarding cheating in relation to Kohlberg's moral development concept. Social Behavior and Personality, 34, 41-50.

Stephens, J. M. (2018). Bridging the divide: The role of motivation and self-regulation in explaining the judgment-action gap related to academic dishonesty. Frontiers in Psychology, 9, 246.

Stone, T. H., Jawahar, I. M., \& Kisamore, J. L. (2009). Using the Theory of Planned Behavior and justifications to predict academic misconduct. Career Development International, 14(3), 221-241.

Stone, T. H., Kisamore, J. L., Kluemper, D., \& Jawahar, I. M. (2012). Whistle-blowing in the classroom. Journal of Higher Education Theory and Practice, 12(5), 11-26.

Stuhmcke, A., Booth, T., \& Wangmann, J. (2016). The illusory dichotomy of plagiarism. Assessment \& Evaluation in Higher Education, 41, 982-995.

Sykes, G. M., \& Matza, D. (1957). Techniques of neutralization: A theory of delinquency. American Sociological Review, 22, 664-670.

Thoma, S. J. (1994). Moral judgment and moral action. In J. Rest \& D. Narvaez (Eds.), Moral development in the professions: Psychology and applied ethics (pp. 199-211). Erlbaum.

Turiel, E. (2003). Morals, motives, and actions. In L. Smith, C. Rogers, \& P. Tomlinson (Eds.), Development and motivation: Joint perspectives (Monograph Series II, Serial No. 2, pp. 29-40). Leicester, England: British Journal of Educational Psychology.

Turiel, E. (2015). Moral development. In R. M. Lerner (Ed.), Handbook of child psychology and developmental science (Vol. 1, pp. 484-522). New York, NY: John Wiley \& Sons, Inc.

Turiel, E., \& Dahl, A. (2019). The development of domains of moral and conventional norms, coordination in decision-making, and the implication of social opposition. In K. Bayertz \& N. Roughley (Eds.), The normative animal: On the anthropological significance of social, moral, and linguistic norms. Oxford, England: Oxford University Press.

Turiel, E., Hildebrandt, C., \& Wainryb, C. (1991). Judging social issues: Difficulties, inconsistencies, and consistencies. Monographs of the Society for Research in Child Development, 56, 1-116. https://doi. org/10.2307/1166056

Turiel, E., Killen, M., \& Helwig, C. C. (1987). Morality: Its structure, functions, and vagaries. In J. Kagan \& S. Lambs (Eds.), The emergence of morality in young children (pp. 155-243). University of Chicago Press.

Wainryb, C. (1991). Understanding differences in moral judgments: The role of informational assumptions. Child Development, 62, 840-851. https://doi.org/10.2307/1131181

Waltzer, T., Baxley, C., Bareket-Shavit, C., \& Dahl, A. (2018). Reasoning and decision-making behind plagiarism. Talk presented at the 30th Annual Meeting of the Association for Psychological Science, San Francisco, CA.

Waltzer, T., \& Dahl, A. (in press). Students' perceptions and evaluations of plagiarism: Effects of text and context. Journal of Moral Education. https://doi.org/10.1080/03057240.2020.1787961

Waltzer, T., Dahl, A., Samuelson, A., Chen, K., Baxley, C., \& Bareket-Shavit, C. (2019). Narrowing the judgment-action gap: The case of student cheating. Paper presented at the Society for Philosophy and Psychology Annual Meeting, San Diego, CA.

Waltzer, T., Li, N., \& Dahl, A. (2017). Why do students cheat? Exploring reasoning behind past experiences with academic dishonesty. Paper presented at the Annual Jean Piaget Society meeting, San Francisco, CA.

Waytz, A., Dungan, J., \& Young, L. (2013). The whistleblower's dilemma and the fairness-loyalty trade-off. Journal of Experimental Social Psychology, 49, 1027-1033.

Whitley, E. B. (1998). Factors associated with cheating among college students: A review. Research in Higher Education, 39, 235-274.

Woodzicka, J. A., \& LaFrance, M. (2001). Real versus imagined gender harassment. Journal of Social Issues, 57, 15-30. 
Yachison, S., Okoshken, J., \& Talwar, V. (2018). Students' reactions to a peer's cheating behavior. Journal of Educational Psychology, 110, 747-763.

Yardley, J., Rodriguez, M. D., Bates, S. C., \& Nelson, J. (2009). True confessions? Alumni's retrospective reports on undergraduate cheating behaviors. Ethics and Behavior, 19, 1-14.

UCSC Division of Undergraduate Education (2019). Academic misconduct policy for undergraduates. Retrieved from https://ue.ucsc.edu/academic-misconduct.html

Publisher's Note Springer Nature remains neutral with regard to jurisdictional claims in published maps and institutional affiliations. 